\title{
FACTORS AFFECTING EMISSION CONCENTRATIONS IN SMALL HEAT SOURCES
}

Combustion of biomass fuel itself as a renewable energy source does not automatically ensure the best use of its energy content with low emission production. Biomass combustion with bad settings of combustion conditions can be ineffective and with a high production of emissions. The article discusses the impact of various aspects on the power and emission parameters of the heat source. The influence of the amount of combustion air, the temperature of combustion air, the relative humidity of combustion air, the fuel feeding and fuel moisture on thermal power and emission production in automatic boiler for combustion of wood pellets were specifically verified. The results show that appropriate setting of these aspects has an effect on concentration of emissions from the combustion of biomass.

Keywords: Emission, dendromass, temperature of combustion air, fuel moisture, air humidity.

\section{Introduction}

There is nowadays again great interest in more efficient use of energy because requirements for energy resources are ever increasing [1]. To enhance energy self-sufficiency, the increasing focus is on the improvement of power equipment efficiency and use of renewable energy sources [2 and 3]. One of the renewable energy sources is biomass.

\subsection{Biomass combustion}

One of the most commonly used forms of obtaining thermal energy from biomass is its direct combustion. There is possibility to burn wood in the form of logs, wood chips, briquettes and pellets, and also straw of cereals and oilseeds, energy plants in packages, briquettes and pellets [4]. The combustion of biomass fuel itself as a renewable energy source does not automatically ensure the best use of its energy content with low emission production [5]. Biomass combustion with bad settings of combustion conditions can be ineffective and with a high production of emissions.

Effective use of biomass by low-emission production requires the application of high quality technologies and their proper operation [6]. Biomass combustion in a heat source is influenced by several aspects, e.g. type of fuel, the amount and distribution of combustion air, method of combustion, design and regulation of combustion appliance, etc. [7]. All those aspects influence the power and emission parameters of the heat source. Emissions are pollutants arising from the biomass combustion dispersed in the air. The basic emissions are carbon monoxide ( $\mathrm{CO})$, nitrogen oxides $\left(\mathrm{NO}_{\mathrm{x}}\right)$, sulphur dioxide $\left(\mathrm{SO}_{2}\right)$, unburned products known as organic hydrocarbons (OGC) and particulate matters (PM) [8 and 9]. To maintain the environmental friendliness of biomass, states issue measures in the form of emission limits, which have to be respected [10].

\subsection{The aim of the article}

The article deals with the impact of various aspects on the power and emission parameters of the heat source. Special attention is paid to the verification of influence of the amount of combustion air, the temperature of combustion air, the relative humidity of combustion air, the fuel feeding and fuel moisture on thermal power and emission production in automatic boiler for combustion of wood pellets.

\footnotetext{
* ${ }^{1}$ Michal Holubcik, ${ }^{1}$ Radovan Nosek, ${ }^{1}$ Katarína Sulovcova, ${ }^{2}$ Roman Weber 
2. Methods for measuring thermo technical parameters of heat sources

\subsection{Heat source}

An automatic hot water boiler designed to burn wood pellets with a nominal heat output of $18 \mathrm{~kW}$ with a retort burner is used as a heat source. Fuel is supplied from a tightly closed container into the combustion chamber using a screw feeder. The air needed for combustion is forced through a fan into the intake system in the combustion chamber. The combustion of waste products takes place near the cast iron rectifier of flue gas. The regulatory control system of the boiler allows changing control algorithms where it is possible to change the amount of combustion air, operation time and standing time of the screw feeder for the fuel supply.

\subsection{Used fuel}

To minimise measurement mistakes during all the experiments, the fuel with the same properties was used. Wood pallets made from spruce sawdust without bark were used. The fuel was supplied by a company producing $2000 \mathrm{~kg}$ of biofuel per hour. The analysis of biofuels confirmed that the delivered wood pellets meet the specified requirements $\mathrm{A} 1$ in compliance with STN EN 14961-2 [11]. The pellet diameter was $6 \mathrm{~mm}$ and their length did not exceed $40 \mathrm{~mm}$. The moisture content determined in compliance with STN EN 14774 [12] reached the value of 9.98\%. The ash content determined in compliance with STN EN 14775 [13] reached the value of $0.452 \%$. Mechanical resistance (DU) determined in compliance with STN EN 15210 [14] reached the value of $98.67 \%$. The content of fine particles (F) determined in compliance with STN EN 15210 [14] reached the value of $0.239 \%$. The calorific value determined in accordance with STN EN 14918 [15] reached the value of $17.58 \mathrm{MJ} . \mathrm{kg}^{-1}$. The bulk density determined in accordance with STN EN 15103 [16] reached the value of $650 \mathrm{~kg} \cdot \mathrm{m}^{-3}$.

\subsection{Measurement of thermal power of the heat source}

Measurement of the heat source thermal power was performed on an experimental device for testing heat sources (Fig. 1) which consisted of the experimental heat source, equipment for heat consumption or regulation of heat produced by the hot water boiler, gaseous emission analyser, particulate matter analyser, logger connected with all the measuring devices which recorded the values every 20 seconds and a PC for evaluation of the measured data.

Thermal power of the heat source is determined in accordance with STN EN 303 - 5 [17]. Direct method, so called calorimetric method, was used to determine the thermal power of the heat source. Thermal power is determined from the mass flow measured by a magnetic induction flow meter and from the temperature difference between outlet and inlet of heat transfer medium in the heat source measured by paired metal resistance thermometers PT100 according to equation [18]:

$Q=m \cdot c_{p} \cdot\left(T_{2}-T_{1}\right)$

where $\mathrm{Q}$ is thermal power of heat source $[\mathrm{kW}], \mathrm{m}$ is mass flow of heat transfer medium at the inlet and outlet $\left[\mathrm{kg} \cdot \mathrm{s}^{-1}\right], \mathrm{c}_{\mathrm{p}}$ is specific heat capacity of heat transfer medium $\left[\mathrm{J} \cdot \mathrm{kg}^{-1} \cdot \mathrm{K}^{-1}\right]$. Specific heat capacity is dependent on the temperature of the heat transfer medium; $\mathrm{T}_{1}$ is temperature of heat transfer medium at the outlet of heat source $[K]$ and $T_{2}$ is temperature of heat transfer medium at the inlet of heat source $[\mathrm{K}]$. During the determination of thermal power it was necessary to maintain the set temperature gradient by the temperature regulator. The regulating device consists of a heat exchanger, two circulation pumps controlled by frequency converters, two regulating valves and of control, regulatory and safety devices. During the measurements the constant chimney draft $12 \pm 2 \mathrm{~Pa}$ was ensured with a flue fan. The flue fan speed was controlled by the frequency converter.

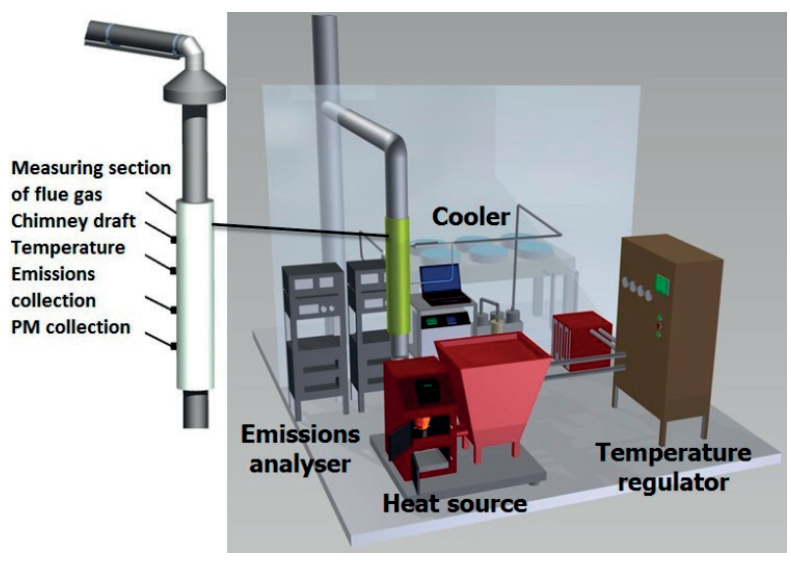

Fig. 1 Experimental device for testing heat sources

\subsection{Measurement of emission production}

The flue gases pass through the measuring section (Fig. 1) which is located in the flue system. In the measuring section of the flue gas the temperature measurement in the chimney, composition of the flue gases and chimney draft measurements were performed. The flue system is joined with an insulated flue gas measurement section. The production of $\mathrm{CO}$ and $\mathrm{NOx}$ was determined by the flue gas analyser ABB AO 2020 [19]. The device works on the principle of infrared spectroscopy. The normalised oxygen concentration $\left(\mathrm{O}_{2}\right.$ standardised $)$ in the flue gases from the central heat source has in accordance with 
STN EN 303 - 5 [17] the value of $10 \%$. The values of emission production were calculated based on the oxygen content in the flue gas according to the relation:

$Y_{\left(10 \% O_{2}\right)}=Y \cdot \frac{21-O_{2 \text { standardised }}}{21-O_{2 \text { avg }}}$

where $\mathrm{Y}$ is the measured concentration of the emission $\left[\mathrm{mg} \cdot \mathrm{m}^{-3}\right]$, $O_{2 \text { standardised }}$ is normalised oxygen concentration [\%] and $O_{2 \text { avg }}$ is the average oxygen concentration in the flue gases[\%].

\section{Methodology for determining the influence of various aspects of the thermo - technical parameters of the heat source}

\subsection{Influence of the amount of combustion air}

The tested boiler conception allowed regulating the amount of combustion air by the control system of the boiler via the fan speed controlled in the range of $10 \%-100 \%$. Regulation for fuel feeding was set at each measurement at the same value (18 seconds feeding and 25 seconds waiting time of the screw feeder) it means that fuel delivery was the same for all measurements.

The combustion air supplied by a fan in the area of retort burner was divided into primary and secondary combustion air. The amount of supplied air to the combustion process was measured by indirect method through an anemometer which measured the air flow velocity at inlet. Based on the velocity and flow section, the volume flow was calculated and, consequently, the mass flow of combustion air was calculated. Mass flow rate of combustion air supplied to the boiler reached the values ranging from $45 \mathrm{~kg} \cdot \mathrm{h}^{-1}$ (for setting the fan at $10 \%$ of rated speed) to 142 $\mathrm{kg} \cdot \mathrm{h}^{-1}$ (for setting the fan at $100 \%$ of rated speed).

\subsection{Influence of the combustion air temperature}

Combustion air temperature change was performed before entering the heat source. Combustion air supply was connected to the pipe with the heat exchanger which heats or cools supplied combustion air. The lowest supplied air temperature was $-5^{\circ} \mathrm{C}$ and gradually increased in steps of $5^{\circ} \mathrm{C}$ to $40^{\circ} \mathrm{C}$. Regulation for supply air temperature was set during measurement at the same value (18 seconds feeding and 25 seconds waiting time of the screw feeder, the fan was set at $40 \%$ of rated speed).

The heat exchanger was located behind the fan in a square duct made of steel sheet with service door. The heat exchanger was made of copper tubing with corrugated aluminium ribs used for better heat transfer. The size of aluminium ribs is $60 \mathrm{x} 120 \mathrm{x}$ $0.5 \mathrm{~mm}(\mathrm{v} \times \mathrm{dxh})$ with regular spacing $5 \mathrm{~mm}$. The heat exchanger consists of four separate parts having the length of $170 \mathrm{~mm}$. All four parts are connected by copper elbows into a single unit while soldering is done by brazing. Inlet and outlet of heat from the heat exchanger is done by heat transfer medium - Thermal Glycol mixture with water in 1:1 ratio with solidification point $-30{ }^{\circ} \mathrm{C}$. Regulation of the fluid temperature was carried out by a circulating thermostat Julabo FP40 which was connected through the insulated pipe to the heat exchanger. The scheme of device for change of combustion air temperature is shown in Fig. 2.

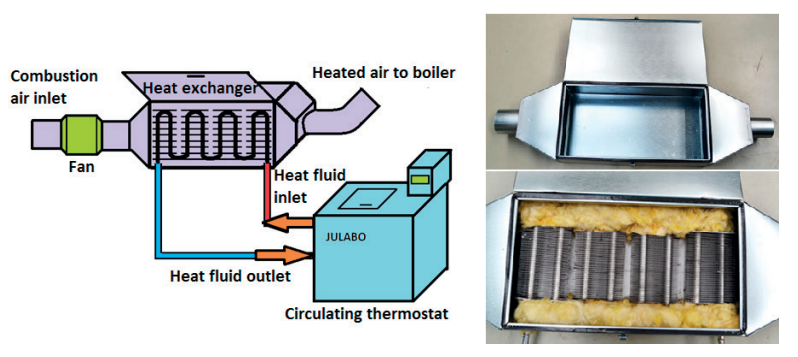

Fig. 2 The principle of combustion air heating

\subsection{Influence of the relative humidity on combustion air}

The relative humidity of combustion air was regulated in the polystyrene chamber with the following dimensions $1.5 \mathrm{~m} \times 1.0 \mathrm{~m}$ x 1.0m (Fig. 3). Ambient air having a relative humidity $49 \%$ and temperature of $23^{\circ} \mathrm{C}$ was fed into the chamber. The water vapour was produced in a steam humidifier with the regulation of the relative humidity. The chamber was equipped with separating walls for more efficient mixing of ambient air with water vapour. The relative humidity of the combustion air was measured just before accession to the boiler and the examined values were as follows: $50 \%, 60 \%, 70 \%, 80 \%, 90 \%$ and $99 \%$. The humidity of air progressed according to Mollier $\mathrm{h}$-x diagram isothermally when to increase the relative humidity from $49 \%$ (at $23^{\circ} \mathrm{C}$ ) to $60 \%$ at a constant temperature, it was necessary to bring $2 \mathrm{~g}$ of water vapour per $1 \mathrm{~kg}$ of air. Combustion air temperature at the inlet to the heat source was the same as the temperature at the inlet to the polystyrene chamber.

Settings for the fuel supply and combustion air were the same for each measurement ( 18 seconds feeding, 25 seconds standing of the fuel conveyor, the fan was set at $40 \%$ of rated speed).

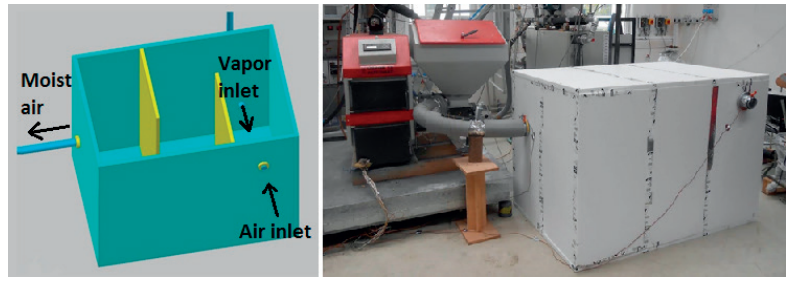

Fig. 3 The principle of combustion air humidification 
Average values of combustion air mass flow, heat output, $\mathrm{CO}$ and NOx formation depending on the fan setting

Table 1

\begin{tabular}{|l|c|c|c|c|c|c|c|c|c|c|}
\hline Fan settings & $\mathbf{1 0} \%$ & $\mathbf{2 0} \%$ & $\mathbf{3 0} \%$ & $\mathbf{4 0} \%$ & $\mathbf{5 0} \%$ & $\mathbf{6 0} \%$ & $\mathbf{7 0} \%$ & $\mathbf{8 0} \%$ & $\mathbf{9 0} \%$ & $\mathbf{1 0 0} \%$ \\
\hline Mass flow rate $\left[\mathrm{kg} \cdot \mathrm{h}^{-1}\right]$ & 45 & 72 & 90 & 108 & 114 & 137 & 139 & 139 & 140 & 142 \\
\hline Thermal power $[\mathrm{kW}]$ & 14.01 & 14.92 & 15.84 & 17.12 & 16.91 & 16.48 & 16.02 & 15.48 & 14.95 & 14.84 \\
\hline CO concentration $\left[\mathrm{mg} \cdot \mathrm{m}^{-3}\right]$ & 9554 & 351 & 340 & 547 & 1328 & 1748 & 1697 & 1976 & 3330 & 3646 \\
\hline NOx concentration $\left[\mathrm{mg} \cdot \mathrm{m}^{-3}\right]$ & 94 & 178 & 174 & 173 & 165 & 171 & 177 & 179 & 169 & 170 \\
\hline
\end{tabular}

\subsection{Effect of fuel moisture}

In this section we investigated the influence of fuel humidity on thermo-technical parameters of the heat source; we did it by changing the humidity of fuel (wood pellets). Wood pellets with an initial moisture content of $9.98 \%$ were subsequently dried to a humidity of $0 \%$ and $5 \%$; gradually adding water, the sample moisture content reached $10 \%, 15 \%, 20 \%, 25 \%$ and $30 \%$. The individual samples were tested in automatic boilers for combustion of wood pellets in the same regulation setting of the boiler; fuel supply ( 18 seconds feeding, 25 seconds standing of the fuel conveyor) and supply of combustion air (fan was set at $40 \%$ of rated speed) remained the same during each measurement.

\subsection{Influence of fuel feeding}

Control of the heat output of small automatic heat sources was done by changing the time of both fuel feeding and combustion of supplied fuel. The recommended setting of fuel supply and combustion time is in many cases based on experience of manufacturers or on measurements of nominal and minimum performance of boiler during testing [20].The user of the heat source has available variety of feeding and combustion time settings.

The tested automatic hot water boiler for burning wood pellets allows changing the operating time and the time of standing of the screw feeder for fuel supply. In the framework of the research three types of comparative measurements were carried out to determine the influence of fuel supply on thermo-technical parameters of the heat source. The first series of measurements was carried out at a constant time standing at 25 seconds and following time of fuel supply 18, 15, 12 and 9 seconds. The second series of measurements was carried out at a constant fuel supply of the 18 seconds and the standing times of 25, 28, 31 and 34 seconds. The third series of measurements was carried out at a constant time difference of 7 seconds between the time of fuel supply and standing time. The settings during the third measurements were as follows: 15/22 sec. (standing / supply), 18/25 sec., 20/27 sec. and $30 / 37 \mathrm{sec}$. The supply of combustion air was constant for all the measurements (the fan was set at $40 \%$ of rated speed).

\section{Results of experiments}

\subsection{Amount of combustion air}

Table 1 shows the average values of the combustion air mass flow, heat output, concentration of $\mathrm{CO}$ and NOx depending on the setting of the fan speed. The mass flow rate of combustion air increased proportionally to the increasing fan speed up to $60 \%$ of rated speed. The slightest increase in mass flow of the fan was recorded in the range of $60 \%$ to $100 \%$ of rated speed. Thermal power of the heat source increased with the fan speed to the value of $40 \%$, subsequently it declined. The highest $\mathrm{CO}$ production was recorded at $10 \%$ of the fan speed which was caused by low excess air or incomplete combustion due to insufficient supply of oxygen to the flame.

The lowest $\mathrm{CO}$ concentrations were registered at the value of $20 \%$ and with the increasing amount of combustion air the CO formation increased as well. The NOx concentration was lowest in the minimum amount of combustion air, given by the small amount of nitrogen supplied to air and due to a lower temperature in the flame [21]. For other speeds the formation of NOx did not change much.

\subsection{The temperature of combustion air}

Table 2 shows the average values of heat power, concentration of $\mathrm{CO}$ and NOx depending on the temperature of combustion air. The boiler thermal power increased with the rising combustion air temperature due to the supply of certain energy into the warmer air. The $\mathrm{CO}$ concentration decreased with the increasing combustion air temperature due to a higher temperature in the combustion chamber and burning of $\mathrm{CO}$ to $\mathrm{CO}_{2}$. The lowest NOx concentration was recorded at the lowest temperature of the combustion air; as the temperature raised the NOx formation increased. This was caused by high flame temperature when more NOx was formed [21 and 22]. 
Average values of heat output, $\mathrm{CO}$ and NOx formation depending on the combustion air temperature

Table 2

\begin{tabular}{|l|c|c|c|c|c|c|c|c|c|c|}
\hline Combustion air temperature & $-5{ }^{\circ} \mathrm{C}$ & $0{ }^{\circ} \mathrm{C}$ & $5{ }^{\circ} \mathrm{C}$ & $10{ }^{\circ} \mathrm{C}$ & $15{ }^{\circ} \mathrm{C}$ & $20{ }^{\circ} \mathrm{C}$ & $25{ }^{\circ} \mathrm{C}$ & $30{ }^{\circ} \mathrm{C}$ & $35^{\circ} \mathrm{C}$ & $40{ }^{\circ} \mathrm{C}$ \\
\hline Thermal power $[\mathrm{kW}]$ & 16.92 & 17.02 & 17.41 & 17.56 & 17.73 & 17.91 & 18.06 & 18.14 & 18.21 & 18.39 \\
\hline CO concentration $\left[\mathrm{mg} \cdot \mathrm{m}^{-3}\right]$ & 468 & 537 & 511 & 487 & 479 & 421 & 436 & 396 & 409 & 378 \\
\hline NOx concentration $\left[\mathrm{mg} \cdot \mathrm{m}^{-3}\right]$ & 154 & 159 & 158 & 164 & 173 & 171 & 178 & 181 & 183 & 187 \\
\hline
\end{tabular}

\subsection{Relative humidity of combustion air}

Table 3 shows the average values of thermal power, $\mathrm{CO}$ and NOx formation depending on the relative humidity of combustion air. Higher humidity of combustion air caused the cooling of flame and it resulted in the reduction of thermal power. The experimental results also show that $\mathrm{CO}$ had a slightly rising trend. However, at $99 \%$ humidity the concentration of $\mathrm{CO}$ was more than seven times higher due to a lower flame temperature and imperfect combustion (less oxygen at the expense of the water vapour). From the results it can be seen that the NOx production is slightly decreasing with increasing air humidity caused by the cooling of the flame by water contained in the moist air. In the case of $99 \%$ air humidity the production of NOx decreased by more than $20 \%$.

\subsection{Effect of fuel moisture}

Dependence of the average values of thermal power and emissions on fuel moisture is shown in Table 4. As expected, the boiler capacity decreased significantly with increasing moisture content of fuel due to a lower amount of flammable products in the humid fuel. In this case some energy was used to evaporate water during combustion. Table 3 shows that the $\mathrm{CO}$ production had increasing character with increasing moisture content of fuel. CO concentrations were 16times higher at 30\% moisture content of fuel compared to the combustion of dry fuel. This was due to imperfect mixing of fuel with an oxidant, creating zones in the combustion chamber of the furnace with the lack of oxygen for total oxidation of the carbon, the instability of the temperature conditions in the combustion chamber of the furnace and temperature variations in the furnace because of the water content of the fuel. A significant decrease in NOx was observed with increasing moisture content of fuel due to the flame cooling by water contained in the wet fuel.

\subsection{Influence of fuel feeding}

Tables 5, 6 and 7 show the average values of thermal power, $\mathrm{CO}$ and NOx concentrations depending on the setting of fuel feeding. The measurements showed that the effect of setting the fuel feeding and fuel burning time (standing) had a major impact on the performance and emission parameters of the heat source. Reducing the time of fuel feeding at constant standing time had a linear effect on the heat output. The measurements of boiler at operating settings showed that the highest thermal performance was achieved in the following setting - 18/25 seconds (feeding/ standing). The highest formation of $\mathrm{CO}$ was measured while achieving the maximum heat output of the heat source. For other settings of the boiler significantly lower concentrations of $\mathrm{CO}$ were measured. It follows that the nominal power would be needed to bring to the furnace higher amount of secondary air so as to deflagrate relatively large amounts of $\mathrm{CO}$. The results of measuring the NOx concentration indicated that these are essentially constant and of relatively low value.

Average values of heat output, $\mathrm{CO}$ and NOx formation depending on the combustion air humidity

Table 3

\begin{tabular}{|l|c|c|c|c|c|c|c|}
\hline Combustion air humidity & $\mathbf{4 9} \%$ & $\mathbf{5 0} \%$ & $\mathbf{6 0} \%$ & $\mathbf{7 0} \%$ & $\mathbf{8 0} \%$ & $\mathbf{9 0} \%$ & $\mathbf{9 9} \%$ \\
\hline Thermal power $[\mathrm{kW}]$ & 16.91 & 16.90 & 16.8 & 16.6 & 16.5 & 16.4 & 16.2 \\
\hline CO concentration $\left[\mathrm{mg} \cdot \mathrm{m}^{-3}\right]$ & 470 & 471 & 474 & 538 & 572 & 585 & 3381 \\
\hline NOx concentration $\left[\mathrm{mg} \cdot \mathrm{m}^{-3}\right]$ & 320 & 319 & 317 & 315 & 312 & 309 & 252 \\
\hline
\end{tabular}

Average values of heat output, $\mathrm{CO}$ and NOx formation depending on the fuel moisture

Table 4

\begin{tabular}{|l|c|c|c|c|c|c|c|}
\hline Fuel moisture & $\mathbf{0} \%$ & $\mathbf{5 \%}$ & $\mathbf{1 0} \%$ & $\mathbf{1 5} \%$ & $\mathbf{2 0} \%$ & $\mathbf{2 5} \%$ & $\mathbf{3 0} \%$ \\
\hline Thermal power $[\mathrm{kW}]$ & 19.21 & 18.08 & 17.28 & 15.95 & 12.36 & 9.74 & 7.99 \\
\hline CO concentration $\left[\mathrm{mg} \cdot \mathrm{m}^{-3}\right]$ & 268 & 322 & 355 & 784 & 1372 & 1978 & 4299 \\
\hline NOx concentration $\left[\mathrm{mg} \cdot \mathrm{m}^{-3}\right]$ & 207 & 199 & 181 & 173 & 154 & 119 & 97 \\
\hline
\end{tabular}


Average values of heat output, $\mathrm{CO}$ and NOx formation depending on the fuel supply

\begin{tabular}{|l|c|c|c|c|}
\hline Fuel supply & $\mathbf{1 8 / 2 5} \mathbf{s}$ & $\mathbf{1 5 / 2 5} \mathbf{~ s}$ & $\mathbf{1 2 / 2 5} \mathbf{~ s}$ & $\mathbf{9 / 2 5} \mathbf{~ s}$ \\
\hline Thermal power $[\mathrm{kW}]$ & 17.93 & 15.42 & 11.91 & 9.24 \\
\hline CO concentration $\left[\mathrm{mg} \cdot \mathrm{m}^{-3}\right]$ & 451 & 327 & 242 & 287 \\
\hline NOx concentration $\left[\mathrm{mg} \cdot \mathrm{m}^{-3}\right]$ & 164 & 176 & 168 & 164 \\
\hline
\end{tabular}

Table 6

\begin{tabular}{|l|c|c|c|c|}
\hline Fuel supply & $\mathbf{1 8 / 2 5} \mathbf{s}$ & $\mathbf{1 8 / 2 8} \mathbf{~ s}$ & $\mathbf{1 8 / 3 1} \mathbf{~ s}$ & $\mathbf{1 8 / 3 4} \mathbf{~ s}$ \\
\hline Thermal power $[\mathrm{kW}]$ & 17.93 & 15.63 & 13.74 & 12.03 \\
\hline CO concentration $\left[\mathrm{mg} \cdot \mathrm{m}^{-3}\right]$ & 451 & 283 & 224 & 235 \\
\hline NOx concentration $\left[\mathrm{mg} \cdot \mathrm{m}^{-3}\right]$ & 164 & 171 & 172 & 169 \\
\hline
\end{tabular}

Table 7

\begin{tabular}{|l|c|c|c|c|}
\hline Fuel supply & $\mathbf{1 5 / 2 2} \mathbf{~ s}$ & $\mathbf{1 8 / 2 5} \mathbf{~ s}$ & $\mathbf{2 0 / 2 7} \mathbf{~ s}$ & $\mathbf{3 0 / 3 7} \mathbf{~ s}$ \\
\hline Thermal power $[\mathrm{kW}]$ & 15.54 & 17.93 & 15.87 & 14.26 \\
\hline CO concentration $\left[\mathrm{mg} \cdot \mathrm{m}^{-3}\right]$ & 356 & 451 & 398 & 411 \\
\hline NOx concentration $\left[\mathrm{mg} \cdot \mathrm{m}^{-3}\right]$ & 183 & 164 & 181 & 184 \\
\hline
\end{tabular}

\section{Conclusion}

The results of experiments pointed out the fact that the combustion process can influence many aspects. Measurements show that these aspects affect the thermal performance of the heat source and the formation of CO and NOx. The obtained results (Fig. 4) show that the humidity of fuel has the highest impact on the combustion process. This factor significantly decreases the thermal power of the boiler and considerably increases the production of $\mathrm{CO}$.

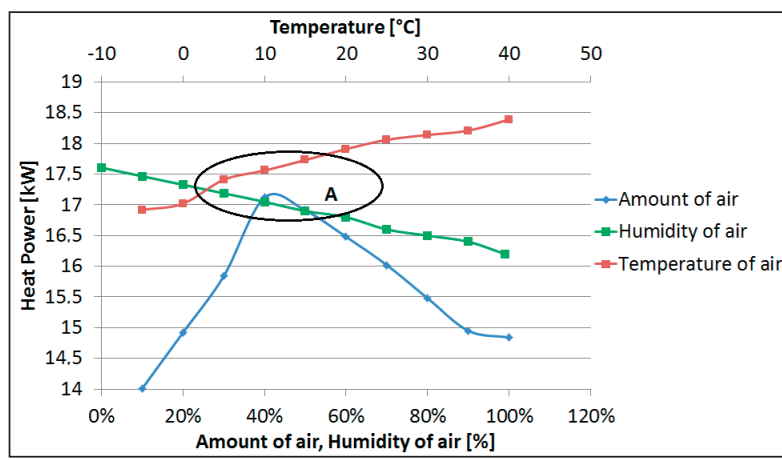

Fig. 4 Graph of thermal power dependence on different aspects (area A shows standard conditions of biomass combustion)

The amount of combustion air and its properties also have relatively significant effect on the combustion process. For optimal combustion of biomass it is necessary to ensure appropriate excess air given by the combustion stoichiometry (the lowest relative humidity and the highest temperature of combustion air). Area A (Fig. 4) indicates the optimal combustion conditions of the tested boiler when it is possible to achieve the ideal combination of high thermal power, low emission formation of commercially available fuel (wood pellets have a normal humidity around 10\%) and air (combustion air temperature is normally about $15-20^{\circ} \mathrm{C}$ and relative humidity of about $40-60 \%$ ). Based on the measured results we can conclude that the combustion process is influenced by many factors. For achieving the highest combustion efficiency with the lowest impact on the environment it is necessary to operate the heat source at optimal parameters.

\section{Acknowledgement}

This work was supported by the projects „Vyskumne centrum Zilinskej univerzity v Ziline ITMS 26220220183” and "Moderne zdroje tepla pre vykurovanie "KEGA 070ZU-4/2013.

\section{References}

[1] MESKO, J., FABIAN, P., HOPKO, A., KONAR, R..: Shape of Heat Source in Simulation Program SYSWELD using Different Types of Gases and Welding Methods. Strojirenska technologie, vol. 16, No. 5, 2011, 6-11.

[2] KAPJOR, A., HUZVAR, J., FTOREK, B., VANTUCH, M.: Criterion Equations of Heat Transfer for "n" Horizontal Pipes one above another at Natural Convection in Linear Method of Approximation, Communications - Scientific Letters of the University of Zilina, vol. 16, No. 3A, 2014, 54-61.

[3] PILAT, P., PATSCH, M., MALCHO, M.: Solar Heat Utilization for Adsorption Cooling Device, EPJ Web of Conferences, vol. $25,2012$.

[4] CERNECKY, J., NEUPAUEROVA, A., JANOSKO, I., SOLDAN, M.: Environmental Technology (in Slovak), Technicka univerzita Zvolen, 274 p., 2010.

[5] DELIISKI, N., DZURENDA L., BREZIN V.: Calculation of the Heat Energy needed for Melting of the Ice in Wood Materials for Veneer Production, Acta Facultatis Xylologiae Zvolen vol. 55, No. 2, 2013, 21-32.

[6] SOOS, L., KOLEJAK, M., URBAN, F.: Biomass - Renewable Energy Source (in Slovak),Vert: Bratislava, 2012.

[7] HUZVAR, J., KAPJOR, A.: Micro-cogeneration incl. the Conversion of Chemical Energy of Biomass to Electric Energy and the Low Potential Heat, Proc. of AIP Conference, vol. 1337, 2011, 40-42. 


\section{COMMNICOIIONS}

[8] VITAZEK, I., VITAZKOVA, B., PLOTH, J.: Production of Gas Emissions from Biomass Heat Source. Engineering Mechanics, vol. 20, 2013, No. 3/4, 289-298. ISSN 1805-4633.

[9] TAUS, P., TAUSOVA, M.: Economic Analysis of FV Power Plants According to Installed Performance, Acta Montanistica Slovaca, vol. 14, No. 1, 2009

[10] DZURENDA, L., DELIISKI, N.: Drying of Beech Timber in Chamber Drying Kilns by Regimes Preserving the Original colour of wood, Acta Facultatis Xylologiae Zvolen, vol. 55 No. 2, 2013, 31-42.

[11] STN EN 14961-2, 2011: Solid biofuels. Fuel specifications and classes. Part 2: Wood pellets for non-industrial use

[12] STN EN 14774, 2010: Solid biofuels. Determination of moisture content. Oven dry method

[13] STN EN 14775, 2010: Solid biofuels. Determination of ash content

[14] STN EN 15210, 2010: Solid biofuels. Determination of mechanical durability of pellets and briquettes.

[15] STN EN 14918, 2010: Solid biofuels. Determination of calorific value

[16] STN EN 15103, 2010: Solid biofuels. Determination of bulk density

[17] STN EN 303 - 5: 2012: Heating boilers. Part 5: Heating boilers for solid fuels, manually and automatically stoked nominal heat output of up to $500 \mathrm{~kW}$. Terminology, requirements, testing and marking

[18] NEMEC, P., CAJA, A., MALCHO, M.: Mathematical Model for Heat Transfer Limitations of Heat Pipe, Mathematical and Computer Modelling, vol. 57, No. 1-2, 2013, 126-136.

[19] HORAK, J., JANKOVSKA, Z., STRAKA, F., BURYAN, P., KUBESA, P., HOPAN, F., KRPEC, K.: Problems of Determination of Characteristic Temperatures of Biomass Ash Fusibility (in Czech), Chemicke listy, vol. 107, No. 6, 2013, 502-509.

[20] WERLE, S.: Impact of Feedstock Properties and Operating Conditions on Sewage Sludge Gasification in a Fixed Bed Gasifier, Waste Management \& Research, vol. 32 (10), 2014, 954-960.

[21] RIMAR, M., FEDAK, M., DUDINAK, P.: Process of Nitrogen Oxides Generation in Pressure Burners, Manufacturing and Industrial Engineering, No. 3, 2007, 81 - 84.

[22] ADAMCZYK, W., WERLE, S., RYFA, A.: Application of the Computational Method for Predicting NOx Reduction within Large Scale Coal-fired Boiler, Applied Thermal Engineering, vol. 73, 2014, 341-348. 